detention) or another consultant at the hospital concerned, preferably one who does not share a ward with the patient's RMO.

The Royal London Hospital, St Clement's

2a Bow Road, London E3 4LL

\section{Breakaway techniques}

\section{DEAR SIRS}

In response to the recent Report of the Collegiate Trainees' Committee Working Party on training of junior psychiatrists with respect to violent incidents (Psychiatric Bulletin, 1991, 15, 243-246) we would like to share our experience at York.

Several measures have been implemented to help ensure safety, including written information regarding the management of potential violence on joining the training scheme, installation of emergency bells in consulting rooms and the formalised reporting of violent incidents. In addition, occasional guest lectures on the assessment and management of violent patients have been arranged.

The most useful measure, however, has been the Breakaway Techniques Course which we have arranged for trainee and senior medical staff. The breakaway techniques are designed to enable the professional working in isolation to safely remove themselves from the following form of attack: hair pulling, strangulation, grasping of clothing, 'bear hugs', and wrist grips.

We have attended one course comprising two half days so far. The course instructors were Home Office approved nursing colleagues who also teach control and restraint for the nursing staff. Originally, the junior doctors felt that training in control and restraint would be useful as often they are present at potentially dangerous situations on the ward. The junior doctors feel helpless while nursing colleagues are trying to restrain physically aggressive or violent patients on the Ward. However, due to the time commitment necessary for the Control and Restraint Course, the Breakaway Techniques Course was the best next alternative. However, we had difficulty in organising breakaway techniques due to the intransigence of senior nurse management with regard to releasing the instructors from their ward duties without reimbursement for their time. After protracted negotiation with the nursing hierarchy we were able to overcome this hurdle without any financial implications.

Once arranged, the course proved a success. Besides learning breakaway techniques, we gained confidence in our ability to deal with the potentially difficult situation and believe that this confidence in itself may prevent 'potential' developing into 'actual'.

It is planned to repeat the course six-monthly so that the new trainees joining the scheme will benefit early in their training and for others it will be a 'refresher'. If the number of medical staff is too small, it may be possible in future for them to join the courses arranged for nurses. We think it is possible for other psychiatric training schemes to organise similar courses with the help of trained nursing colleagues. We gather that other training schemes have also organised such courses and we would strongly suggest still more did so.

Catherine J. Wurr

A. K. Gopalaswamy

North Yorkshire Rotational Training Scheme

in Psychiatry

Bootham Park Hospital

Bootham Park, York YO3 7 BY

\section{Training in neurology}

\section{DEAR SIRS}

I was most interested to read Dr Hughes' article on the value of the physical examination in psychiatry (Psychiatric Bulletin, 1991, 15, 615-616). I am concerned about his findings, in particular with regard to the poor way in which the neurological examination was carried out. I agree with him that it is very important to exclude treatable pathology in the nervous system in psychiatric patients.

I would like to propose two ways of improving the situation.

More emphasis should be placed on training in neurology during postgraduate training for psychiatrists. Perhaps rotational training schemes should include a six month period in a department of neurology. This would also improve the management of psychiatric patients with chronic neurological problems.

The quality of neurological examination would improve if psychiatric units used detailed standardised neurological examination forms, with adequate spaces to note the findings. This is done in many neurology units. The forms I have seen used in psychiatric hospitals to record the physical examination leave very little space to record nervous system findings. (The ones I have seen allowed a quarter of one side of A4 paper for this.)

I feel that the detection of treatable neurological disease is a vital part of the psychiatric evaluation. Perhaps more units should audit this area of practice and changes could then be implemented.

LEON ROZEWICZ

\section{Long Grove Hospital \\ Epsom, Surrey KT198PU}

\section{Use of clozapine}

\section{DEAR SIRS}

I refer to the letter by Ball \& Lipsedge (Psychiatric Bulletin, 1991, 15, 645-646), concerning the use of 